\title{
Developing, Implementing and Communicating Inter- and Transdisciplinary Research: AlpFUTUR as an Example
}

Irmi Seidl, Rosa Böni, Stefan Lauber, Felix Herzog

\begin{abstract}
Summer grazing and Alpine farming in Switzerland are a complex system under pressure to change. By involving stakeholders and their questions right from the beginning, the inter- and transdisciplinary research programme AlpFUTUR undertook a comprehensive analysis and developed new knowledge and practice-relevant products.
\end{abstract}

\author{
Developing, Implementing and Communicating \\ Inter- and Transdisciplinary Research: \\ AlpFUTUR as an Example \\ GAIA 24/3 (2015): 188-195
}

\begin{abstract}
The recently completed research programme AlpFUTUR studied Swiss summer grazing and Alpine farming in its vast complexity in order to provide information and means to take informed decisions given internal and external developments and pressures. Though the first issues and questions were raised by researchers, these were soon complemented by involving practice and administrative bodies into the research process. This paper informs how the programme (22 projects, 80 researchers and implementation experts, and 56 sponsors) was set up and managed, how practice was involved, and how the research process was guided towards a synthesis and a broad array of products that the various stakeholder groups were able to implement. The paper shows that a successful inter- and transdisciplinary research programme needs a stringent management that ideally reflects some of the complexity of the topic, researchers that are keen on such research, good networks with practice - ideally already existing for some time -, and key players that get involved into the research.
\end{abstract}

Keywords

Alpine farming, design of research programme,

implementation of research, inter- and transdisciplinarity,

summer grazing

\section{Background and Research Questions}

Despite the large area and the agronomic, historical and cultural significance of Switzerland's summer grazing land (box 1, figure 1), there were major gaps in the knowledge of this topic until the AlpFUTUR research programme described here. Although several research projects on summer grazing areas and Alpine farming were conducted prior to 2007, a comprehensive analysis of current issues and problems was lacking. The last nationwide inventory of Alpine farming was conducted between the 1950s and the early 1980s (Werthemann and Imboden 1982). Because summer grazing areas and Alpine farming are under huge pressure to change, there was a need for a comprehensive analysis. The reasons for this pressure include external factors such as societal and political changes, climate change, and internal development processes such as structural change in agriculture and increasing technicality.

AlpFUTUR (key data in box 2, p. 190) was inspired by questions arising from individual researchers' projects and in-depth knowledge: Why do open spaces, especially in summer grazing areas, become forested or invaded by scrub? What effects does summer grazing have on biodiversity, especially given the intensified use of prime locations and extensified use of marginal locations seen in recent years? What has changed since the inventory of Werthemann and Imboden (1982)? What are the prospects for Swiss Alpine farming (figure 2, p. 190)? How does society view Alpine farming, and what are society's needs and expectations?

This article aims to present selected aspects of the design and implementation of the AlpFUTUR inter- and transdisciplinary
Contact: PD Dr. Irmi Seidl | Tel.: +41 447392324 |

E-Mail: irmi.seidl@wsl.ch

Rosa Böni | presently: UNESCO World Heritage Swiss Tectonic Arena Sardona | Sargans | Switzerland | E-Mail: rosa.boeni@unesco-sardona.ch

Dr. Stefan Lauber | presently: Umwelt- und Sicherheitsdepartement | Kriens | Switzerland | E-Mail: stefan.lauber@kriens.ch all: Swiss Federal Institute for Forest, Snow and Landscape Research WSL | Zürcherstr. 111 | 8903 Birmensdorf | Switzerland

Dr. Felix Herzog | Agroscope | Zurich | Switzerland |

E-Mail: felix.herzog@agroscope.admin.ch

(C) 2015 I. Seidl et al.; licensee oekom verlag. This is an Open Access article distributed under the terms of the Creative Commons Attribution License (http://creativecommons.org/licenses/by/3.0), which permits unrestricted use, distribution, and reproduction in any medium, provided the original work is properly cited.
und 
research programme: the process of problem identification and structuring, the programme design, that is, the organisational and conceptional approach, the involvement of key players, and the synthesis of results. To this end, we first explain the understanding of inter- and transdisciplinarity and our choice of approach. Next, we outline the process from preliminary study to project financing, as well as the key elements of the design guiding the realisation of the entire research programme. We then describe how the key players were involved and how the synthesis of research results was produced. Finally, we summarise a number of lessons learnt and offer a brief conclusion.

\section{Inter- and Transdisciplinarity as Research Method}

Transdisciplinarity is a form of research driven by the need to solve real-world problems (Hirsch Hadorn et al. 2008, Ukowitz 2014). Problems of this type are behind the questions mentioned above; they are also mirrored in the issues expressed in the preliminary study (see below). Moreover, a transdisciplinary approach was also appropriate, given that the involvement of key players was essential in order to harness existing knowledge. In the words of Berger et al. (2014, p. 23), in a transdisciplinary approach players from outside the scientific system are included in the process: "research is conducted with, and not about, the people concerned and their organisations". Finally, the varied nature of the topic and the need to focus on common problems required a combination

\section{DESIGN REPORTS}

GAIA frequently publishes the results of transdisciplinary projects. Reporting results leaves little room for discussing the project design and the processes shaping it. However, when a team transcends the borders of academia, involves non-academic partners and does joint work, it is necessary to pay special attention to the question how partners from scientific and non-scientific cultures communicate.

If project partners publish only after completion of the project focussing exclusively on results, knowledge about the ways how successful transdisciplinary projects are structured, what kind of communication architectures they have and how they handle results is not shared. Thus, mutual learning - be it from the best practices available or from difficulties - is hardly possible. GAIA wants to create a space for projects to contribute to a common knowledge base of transdisciplinary project know-how. As Design Reports can be published before a project terminates, teams can learn for themselves from reflecting on transdisciplinary project (communication) architectures and processes. By fostering the exchange on the how of transdisciplinary project design, GAIA provides a platform for a long neglected field of professionalization.

GAIA Design Reports are subject to double-blind peer review and should present original research. ${ }^{a}$ They are an experiment, and we would like to invite all those who do transdisciplinary research to take part in it.

a For more details see www.oekom.de/fileadmin/zeitschriften/ autorenhinweise/Design_Reports_2014.pdf.

\section{Summer Grazing}

Summer grazing (Sömmerung) is the practice of keeping farm animals on pastures which, for climatic reasons, can be used only in the summer months (in Switzerland, around 100 days) (Alpine/summer/summering pastures; a related term is transhumance). Summer grazing pastures are therefore not farmed in the winter half year. Summer grazing areas cover eleven percent of Swiss territory. 95 percent of these lie between 1,000 and 2,500 metres above sea level (figure 1). Alpine farming is essential to the agricultural economy and shapes both the cultural landscape of the summer grazing areas and Switzerland's cultural self-concept. The first written documents on the common use of alpine land (Acta Murensia) date back to 1160.

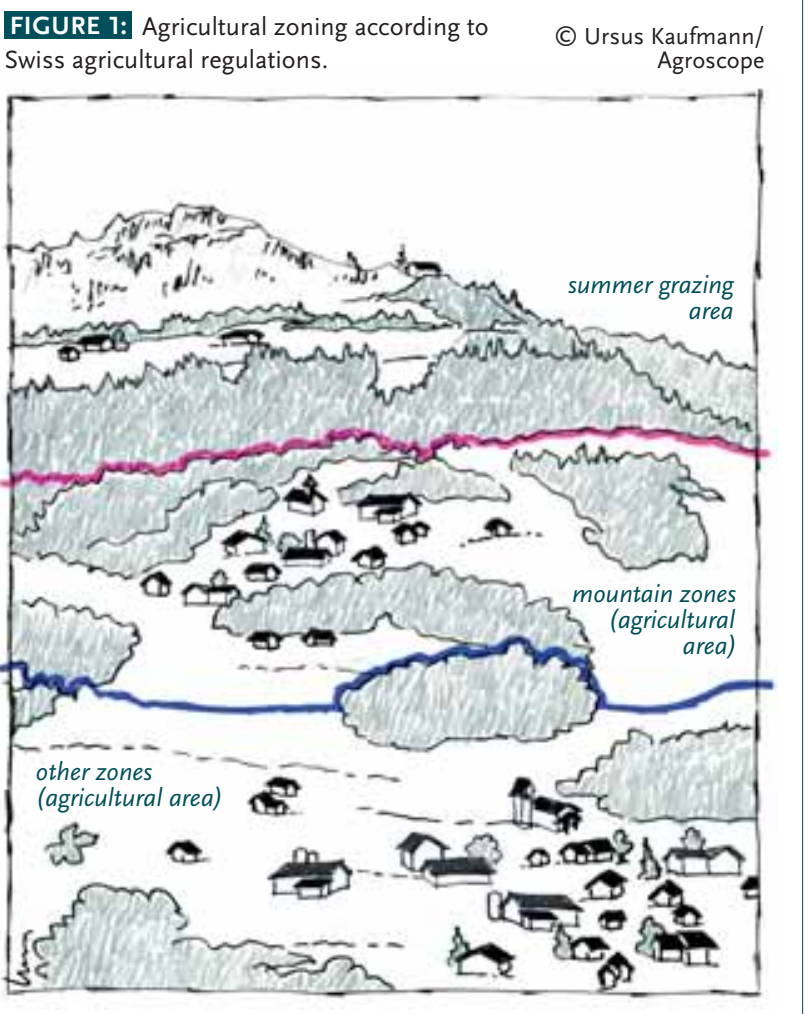

of several scientific disciplines, that is, interdisciplinarity (e.g., Brandt et al. 2013).

By now, there is a wealth of transdisciplinary scientific research (see, e.g., the review by Brandt et al. 2013, see also td-net - Network for Transdisciplinary Research ${ }^{1}$ ) which, inter alia, identifies and analyses research phases and challenges. The classification into three research phases proposed by Pohl and Hirsch Hadorn (2007) is widely accepted. These authors differentiate between problem identification and structuring, problem analysis, and implementation of results (similar phases are identified by others such as Dressel et al. 2014 and Lang et al. 2012). Brandt et al. (2013) identify five key challenges when sustainable science is being implemented as transdisciplinary research: 


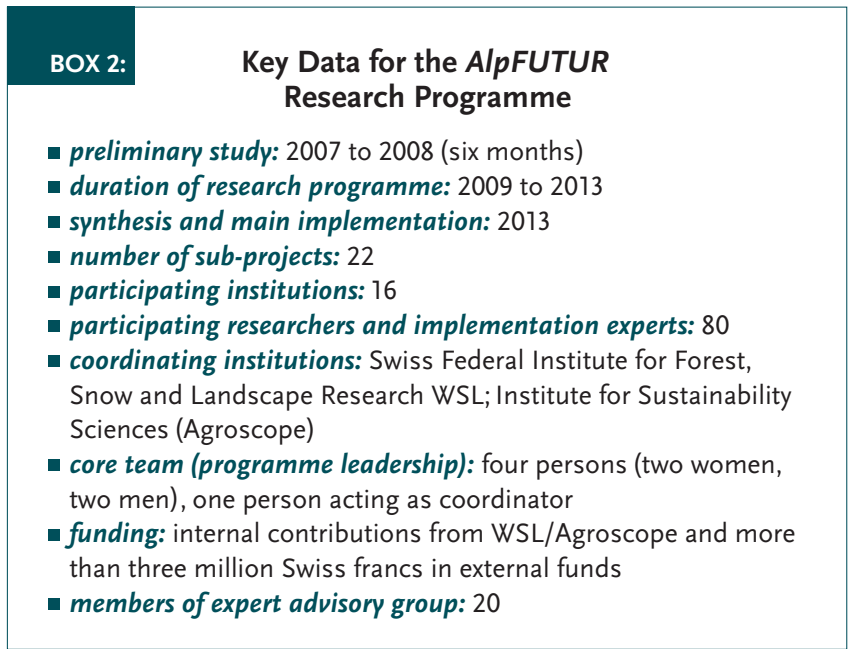

- coherent problem statements and research;

- integration of different disciplinary methods and the development of novel research methods;

- research process and knowledge production;

- involvement of the practitioners, which features different degrees and ideally extends to their empowerment;

- generating impact on practice.

In what follows we will show how AlpFUTUR formed and organised the three research phases - though we will say little about the problem analysis -, and how it faced some of the key challenges, namely the organisation of a coherent problem statement, the research process and knowledge production, the involvement of practitioners, and generating impact on practice.

\section{From Preliminary Study to Financing}

As stated above, there was only scant data available on Swiss summer grazing areas and Alpine farming. Moreover, an overview of the relevant issues raised by research, Alpine farming and relevant government sectors was lacking as well. Thus, first of all, a six-month preliminary study was conducted, financed by both the Swiss Federal Office for Agriculture (FOAG) and the Swiss Federal Office for the Environment (FOEN).

Besides a literature search focusing mainly on "grey literature", the study comprised the following steps for identifying and structuring the problem:

- interviews with stakeholders from the Alpine farming sector (twelve persons) and cantonal authorities (21 persons) as well as a written questioning of Federal Offices (two persons); 150 research questions were distilled from these interviews;

- a workshop with scientists (20 persons) to compile existing and potential research contributions;

- a workshop with stakeholders (eleven persons) and scientists (23 persons) to compile assessments of the topic and research needs and to outline the first few potential projects.

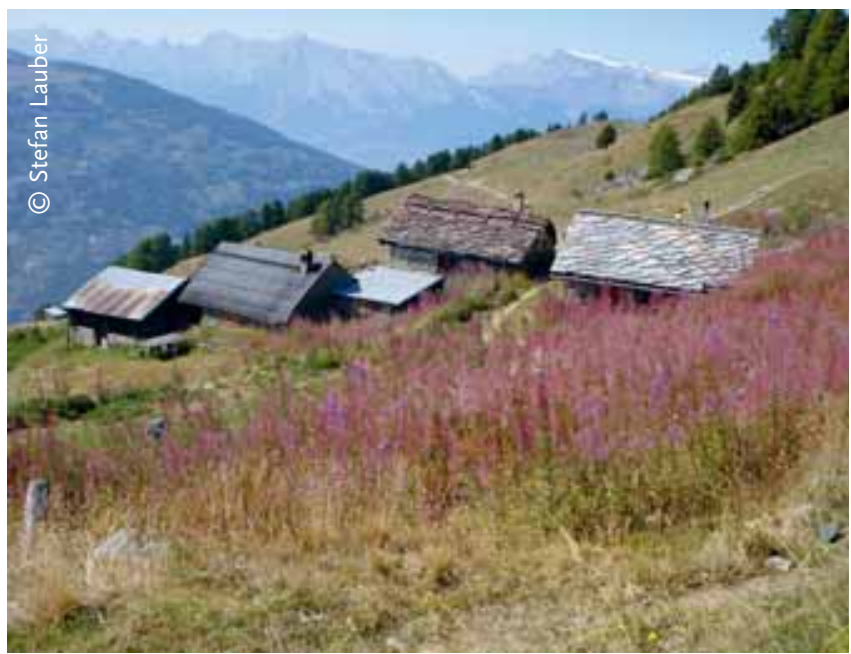

FIGURE 2: Alpine pastures in Eison, Canton of Valais (VS). Here, huts are turned into summer cottages. Overgrown patches and pastured areas are close-by. Elsewhere, intensive use is dominant. What are the prospects for Swiss Alpine farming? Such questions of practical and political importance were the starting point of AlpFUTUR and guided the research process.

A key result of the preliminary study (Lauber et al. 2008) was a model for evaluating the situation and problems facing stakeholders in the Alpine farming system. The need for research was evident, and a research programme emerged as the ideal vehicle. The core team respectively programme leadership team (authors of this article) was formed. The following tasks awaited: producing a rough outline of individual projects, finding people to handle these, designing the programme plan, identifying case-study areas, and obtaining financing. The structuring of the problem was refined over the course of outlining the projects, and a framework for the design and control of the three research phases was formulated as part of the programme plan.

When devising individual projects and searching for people to handle them, the core team focused on the research questions and their importance, needs in practice, implementation into practice, synergies with other research projects, and the interests of potential sponsors. For example, a project was developed on the topic Evaluation of Existing and Alternative Steering Instruments for the Summer Grazing Areas, because no nationwide evaluation of such instruments had been conducted previously, and there was the prospect of an evaluation of these instruments. The core team developed a total of 25 project ideas and approached potentially interested researchers. Those interested produced five- to eightpage project outlines. Some of these did not meet expectations, whereupon the core team approached other researchers and institutions. 19 projects were implemented. Three additional projects not originally planned were added over time (for the list of projects, see Lauber et al. 2013, p. 11) ${ }^{2}$.

Apart from limited staff resources and apart from the professional and supporting infrastructure of the Institute for Sustain-

2 See also www.alpfutur.ch/teilprojekte. 
ability Sciences (Agroscope) and the Swiss Federal Institute for Forest, Snow and Landscape Research WSL, AlpFUTUR initially lacked financial resources to fund the project. Funding was pursued for programme coordination, including synthesis, and for single research projects. To this end, the core team sought to gain an overview of foundations and public authorities with a potential interest in funding inter- and transdisciplinary research on Alpine farming. The responsibility for obtaining project funding lay with the researchers, although the core team supported them in applying and also coordinated the various applications. The search for funding required perseverance and a high frustration threshold. On the one hand, AlpFUTUR was not sufficiently "applied" for some foundations. They wanted to see concrete results, such as a re-introduced species, a refurbished alpine hut or new methods of fencing. On the other hand, most of the project plans did not fit the classical research funding because they were too "applied".

The majority of projects did, however, obtain funding, since many foundations and public authorities are very positively disposed towards Alpine farming and recognised the need for research. A key condition for enabling the programme to go ahead was an initial substantial financial commitment from a foundation. This inspired other foundations and authorities with confidence in the programme's feasibility. In total, 56 sponsors funded the programme to the tune of over three million Swiss francs. Sponsor relations were time-consuming, partly because some private foundations wanted a lot of contact and feedback.

\section{Design of the Programme Plan}

The core team developed a framework for managing and coordinating the various research phases (organisation chart, figure 3). Based in part on experience with previous project consortia and consultation of relevant literature (e. g., Defila et al. 2006, Hirsch Hadorn et al. 2008), the following reflexions and elements were involved.

- Researchers, their projects and key players were to be closely networked in order to develop a shared understanding of the problem, consistent approaches to answer the research questions, and research of practical relevance. To this end, the following instruments were used:

Two Annual Programme Meetings. At the spring workshop (oneday), researchers and core team worked together. They kept one another informed as to the status of the project and the next steps. They discussed partially thought-out ideas, sought solutions to difficulties in individual case-study regions, and reviewed experiences with stakeholders. The autumn workshop (two-day, held in a case-study area) was additionally attended on one day by key players, funding providers, and members of the advisory group (see below). Its main aim was to anchor the programme as a whole among stakeholders, discuss first project results from a critical perspective, and deepen contacts between researchers and key players.

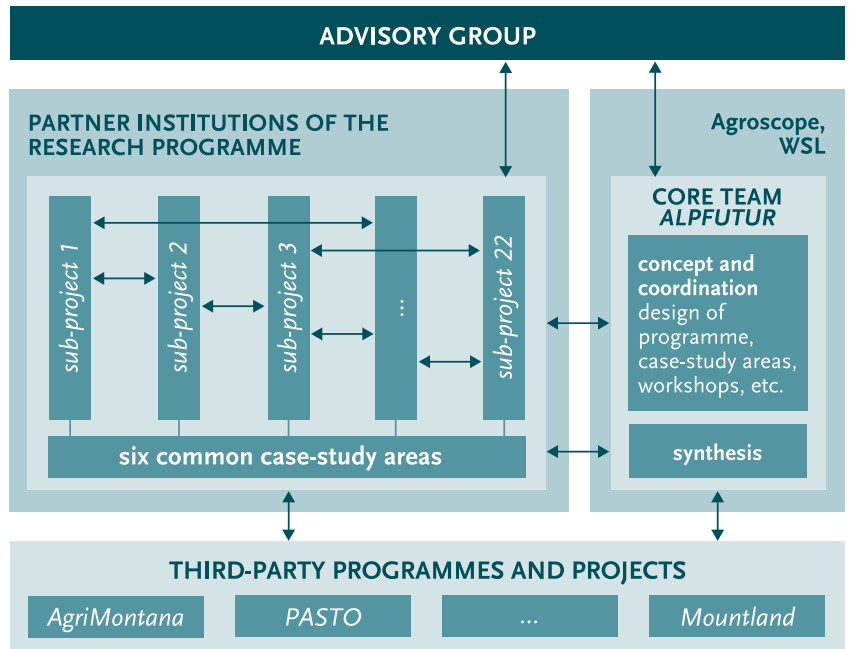

FIGURE 3: AlpFUTUR programme structure. The chart shows cooperation, exchange and consultation between the core team, set up at the Institute for Sustainability Sciences (Agroscope) and the Swiss Federal Institute for Forest, Snow and Landscape Research WSL, the advisory group, the partner institutions of the research programme, and third party programmes.

Selective Site Visits by the Core Team. Around half-way through each project, the core team visited the researchers to discuss the progress made, provide orientation with regard to other projects and information sources, and lend support in planning the project's conclusion. Also beside these visits, the core team inquired about project progress both informally and at the above-mentioned workshops.

Web-based Filing System. As a working tool for sharing and storing documents and data, the system was stocked with content(e. g., from the preliminary study) accessible to all researchers. It was used mainly at the start of the research, becoming less important in the closing stages when information was exchanged directly thanks to close contacts between projects.

Newsletter. Published approximately twice a year in electronic and printed form, the newsletter informed researchers, key players and interested public about new projects, results, publications, etcetera. Easy to set up and maintain, this instrument reached an audience of 450 people.

- Given the topic and the aim of inter- and transdisciplinarity, much of the research was to take place in alpine areas. It was opted to focus on six case-study areas ${ }^{3}$ rather than to do a scattered nationwide research. Case-study areas concentrate the research more effectively, generate synergy effects, and allow closer contact with practice and focused implementation. Selection criteria were the geographical/topographical, cultural and linguistic representation of the Swiss Alpine farming sector (see Lauber et al. 2013, p. $24 \mathrm{ff}$.). The project leaders were advised to focus their activities on the selected areas. This led

3 Vallée de Joux, Canton of Vaud (VD); Diemtig and Niedersimmen Valley, Canton of Berne (BE); Baltschieder, Visper, Nanz and Saas Valley, Canton of Valais (VS); some areas in the Canton of Obwalden (OW); Moesa district, and Lower Engadine, Canton of Grisons (GR). 
to new challenges: contacts with practice had to be coordinated effectively to avoid over-researching and overtaxing these areas.

- To provide a formal framework for collaboration within the programme, the core team devised ten rules for cooperation between individual projects and with the programme coordinators (box 3). These rules were made an integral part of the contracts between research projects, AlpFUTUR, and funding providers.

- Upon conclusion of the programme, and as a key element of the implementation of results, there was to be an overall synthesis. Since the core team intended to work towards this as part of the programme plan, the ten rules codified the expectation that each project would work towards this synthesis from the outset.

- To inform all involved parties and the public, a website ${ }^{4}$ was set up: in three official languages (German, French, Italian), the website provided up-to-date information on projects, publications, deadlines, results, and so forth, and will continue to be updated for ten years after conclusion of the programme. An RSS news feed reported new developments. The core team decided against Facebook and Twitter because the addressees notified did not seem particularly "social-media savvy".

\section{Involvement of and Communication with Key Players}

The involvement of key players (practitioners) is of essential importance for transdisciplinary research: their knowledge, their problems, their commitment to the research process and the practical implementation of results are part of the raison d'être of transdisciplinarity. Brandt et al. (2013) distinguish four degrees of involvement: information, consultation, collaboration and empowerment. AlpFUTUR covered also the last two stages, which are often overlooked.

Practice does not always wait for researchers, however. AlpFUTUR encountered scepticism such as: can researchers and city dwellers ever understand Alpine farming? Another concern was that researchers would represent the agricultural authorities and supply them with arguments for further unpopular regulations.

Hence, special attention was paid to confidence building, personal contacts, openness, furthering knowledge and understanding of the problems (figure 4), and involvement of key players. To this end, the core team took various measures: as already mentioned above, potential research topics were requested, the programme plan was presented initially to alpine and lowland farming circles in all six case-study regions, and the core team shared the task of providing a single point of contact for practice and for contact between practice and researchers for each case-study area. Regular contacts were established with key players such as agri-
BOX 3: Ten Rules for Cooperation between Sub-projects and Programme Coordination (PC)

These rules were an integral part of the contracts.

Programme: The sub-projects are deliberately planned and implemented as part of the AlpFUTUR programme, rather than as individual stand-alone projects.

Project changes: In order to achieve the programme objectives, substantial changes from the project description submitted to funding providers will be made only after consultation with the latter and the PC.

Coordination: In order to ensure that the programme generates relevant added value for science and practice, the individual sub-projects and their basic aims as well as work in the case-study regions (contacts with local population, stakeholders and media) will be actively coordinated. The PC will support this coordination (e.g., through workshops, see following point). At the same time, the sub-projects have a reciprocal duty in terms of coordination and collaboration and will make active efforts in this regard.

Workshop participation: To prepare the synthesis and facilitate synergies between the individual sub-projects, at least one colleague from each sub-project will take part in the biannual programme workshops. Participants will discuss the status of each sub-project and the further course of action within the programme. To this end, the sub-project leaders will prepare the necessary documents or parts of presentations.

Project conclusion: The PC will prepare a synthesis of results from the individual sub-projects. To enable it to do so, the final reports of the individual sub-projects must be available by (date).

Preparation of results: Sub-project leaders will schedule by (date) at least one month of their own or colleagues' working time, specifically in order to draft and prepare the project results and to hold any technical discussions required between sub-project workers and those writing the synthesis.

Delays: If any delays occur in the schedule which may adversely affect the writing of the synthesis, the sub-project leaders will inform the PC immediately so that further action can be discussed.

Reporting: The sub-project leaders will report autonomously to the funding providers as instructed by the latter, and will provide the PC with a copy.

Publicity: In the case of any publications or presentations, and where publication guidelines allow, sub-project leaders and staff will draw attention to the fact that the sub-project is part of the AlpFUTUR programme. The AlpFUTUR logo is available for this purpose. Similarly, funding providers will be listed unless they have expressly declined to be named.

Provision of information: Each sub-project leader will make sure that non-confidential project information of relevance to other sub-projects is made available on the programme's intranet (document management system). Similarly, after consultation with the PC, they will ensure that the information on the AlpFUTUR website on their subject is up-to-date.

cultural schools, Alpine-farming advisory services, and cantonal agricultural offices. In addition, the two-day annual workshop took place in a different case-study area each time, and local players were invited. These workshops also included a half-day excursion into the alpine area. Interim results, final results and recom- 
mendations were discussed in depth with key players. Every opportunity was taken to interact with the latter (e. g., through participation in their meetings). Another important feature was the involvement of an advisory group of experts comprising about 20 individuals from the fields of research, practice and government. These experts helped to establish contacts, contributed towards building confidence in their communities, and discussed results and recommendations with the researchers. Finally, the core team undertook extensive media activities (newspapers, radio, television, specialist journals). Thanks to the early adoption of a simple project name (rather than a baffling acronym) and the consistent use of a logo with an Internet address, AlpFUTUR became a brand. As a result, the projects became identified with the programme, raising public awareness. The above measures - together with a broad product portfolio geared to key players in particular (see table, p. 194), as well as serious research -, fostered a climate of confidence and collaboration, mutual appreciation, close involvement of all parties and empowerment, and ultimately contributed to the fact that the results and findings were taken seriously and put into practice.

\section{Synthesis of Research Results}

For many, a synthesis represents the culmination of an inter- and transdisciplinary research process as it may constitute a central element of the implementation of results (the third research phase). This has already overstretched some research consortia, however, and opinions on completed syntheses are often divided. Synthesis planning needs to start early, in order to align the projects appropriately. AlpFUTUR planned its synthesis right from the outset. It was discussed at the very first annual meeting, where possible contributions for each project were requested and logged.

Just under two years before writing the synthesis began, the core group submitted an initial rough draft to all researchers for discussion. The form finally chosen was a book of carefully coordinated individual contributions to benefit from the expertise of many different researchers. Each chapter had a main author who was also a coeditor of the book and who was chosen by the core team. Each main author coordinated their chapter with their co-authors from the involved sub-projects. Three workshops

FIGURE 4: One of the research questions of AlpFUTUR focused on scrub invasion of summer grazing areas. In order to gain direct experience and learn more about the problem on-site, researchers supported a farmers' family living in Melchtal in the case-study area Obwalden in clearing a recently leased Alpine pasture overgrown with bracken. were held with all of the main authors. The first workshop dealt with the concept for the book (topics, content, authorship, target audience, writing style, publisher, deadlines, etc.). The second discussed and compared drafts and content of the various chapters. The third and final workshop focused on fine-tuning the content and layout, and on selecting and drafting the recommendations. This workshop was attended by a reader who was put in charge of copy editing the entire book. Responsibility for the content of the synthesis lay with the core team.

\section{Lessons Learnt}

The AlpFUTUR case has once again proven that unanswered questions relevant to practice are a promising starting point for transdisciplinary research, rather than the desire for a project per se.

Transdisciplinarity is often described as very laborious and complex (e.g., Winiwarter 2014): AlpFUTUR can confirm this. Such research also requires a great deal of perseverance, and hence time and money. Existing networks of the core team and researchers were of great assistance in setting up the programme and conducting the research. Huber and Rigling (2014) view networks and knowledge thanks to continuous on-the-spot research as a key factor in transdisciplinarity.

The literature on transdisciplinarity makes little mention of the influence of funding sources. These can promote a focus on implementation by making this a condition of funding, and they can also steer content. In the case of AlpFUTUR, it was crucial for projects whose funding providers showed a keen interest in content to maintain regular interaction throughout the research, and to balance the funding providers' interests with research needs. Both sides were altogether satisfied with the final results.

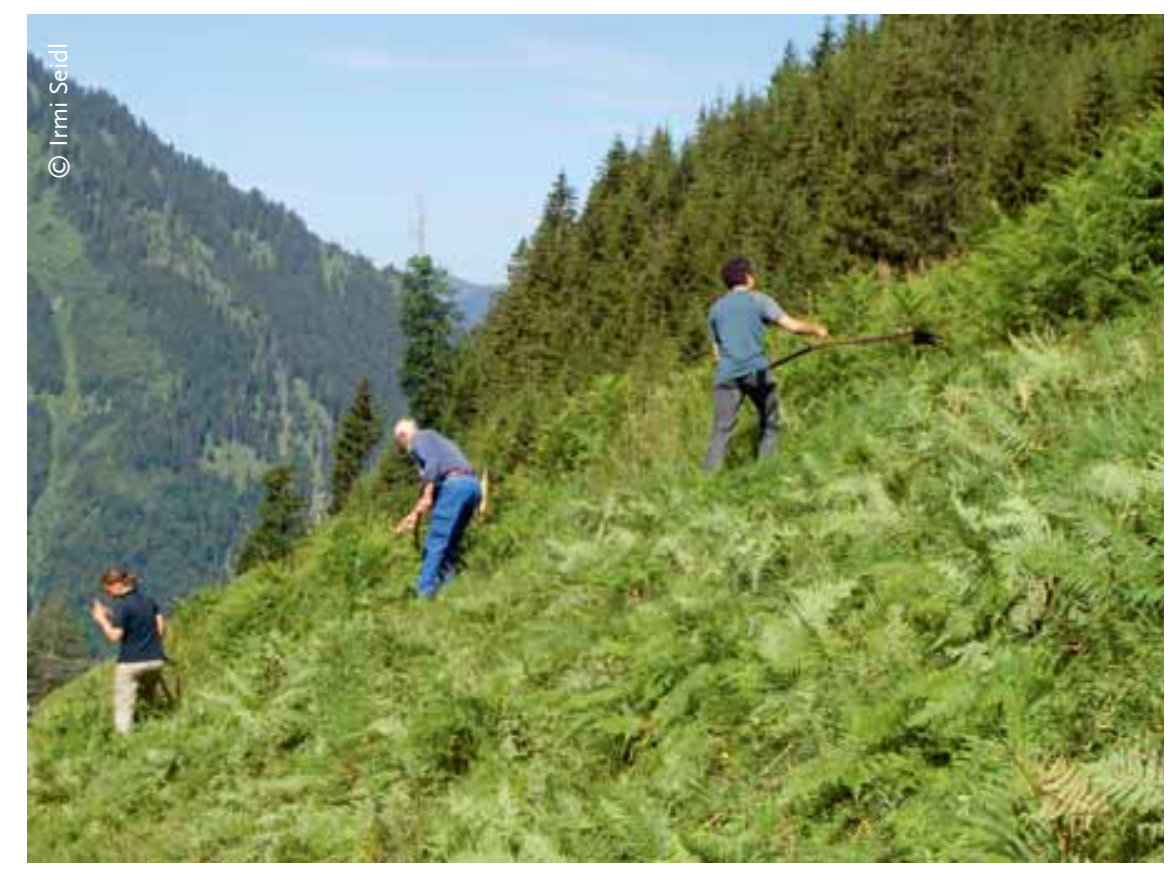


TABLE: Product portfolio and addressees: In transdisciplinary research, involvement of stakeholders is of essential importance. Apart from information and consultation, AlpFUTUR paid special attention to close colllaboration and empowerment of all parties. The research programme, therefore, developed a broad portfolio of practice-relevant products.

\begin{tabular}{|c|c|c|c|c|c|}
\hline PRODUCTS & research & government & $\begin{array}{c}\text { ADDRESSEES } \\
\text { advisory services/training, education }\end{array}$ & Alpine farming & public \\
\hline peer-reviewed specialist articles in English & $\mathrm{x}$ & $\mathrm{x}$ & & & \\
\hline $\begin{array}{l}\text { peer-reviewed specialist articles in Swiss } \\
\text { national languages }\end{array}$ & $\mathrm{x}$ & $x$ & $x$ & & \\
\hline articles in specialist journals & & $\mathrm{x}$ & $x$ & $\mathbf{x}$ & \\
\hline articles in newspapers/journals & & $\mathrm{x}$ & $x$ & $\mathrm{x}$ & $x$ \\
\hline project reports & $x$ & $\mathrm{x}$ & $\mathrm{x}$ & & \\
\hline presentations & $\mathrm{x}$ & $\mathrm{x}$ & $x$ & $\mathrm{x}$ & $x$ \\
\hline consultancy from researchers & & $\mathrm{x}$ & $x$ & $\mathrm{x}$ & \\
\hline academic training ( $\mathrm{PhD}$ and Masters theses) & $x$ & $\mathrm{x}$ & $\mathrm{x}$ & & \\
\hline $\begin{array}{l}\text { new alpine products (e. g., milk sold by } \\
\text { major distributor) }\end{array}$ & & & & $x$ & $x$ \\
\hline Excel tool, full costing for Alpine farms & & & $x$ & $x$ & \\
\hline $\begin{array}{l}\text { smartphone apps for management of livestock } \\
\text { density and for product commercialisation }\end{array}$ & & & & $x$ & $x$ \\
\hline $\begin{array}{l}\text { handbooks for tourism, for development of } \\
\text { infrastructure; inventories of alpine products } \\
\text { and product innovations }\end{array}$ & & $\mathrm{x}$ & $\mathbf{x}$ & $\mathbf{x}$ & \\
\hline AlpFUTUR exhibition stand & & & $x$ & $x$ & $x$ \\
\hline synthesis (book) & $(\mathrm{X})$ & $x$ & $x$ & $x$ & $x$ \\
\hline documentary film & & & $x$ & $x$ & $\mathrm{x}$ \\
\hline implementation films & & & $x$ & $x$ & \\
\hline $\begin{array}{l}\text { gadgets such as AlpFUTUR e-Memory, } \\
\text { internet photo gallery }\end{array}$ & & & & & $x$ \\
\hline website & $x$ & $x$ & $x$ & $x$ & $x$ \\
\hline
\end{tabular}

In transdisciplinary research, the importance of programme management receives inadequate attention. So we recommend that such research should focus more strongly on the importance of programme management. In addition to specialist knowledge, this is vital for the successful completion of a programme.

The composition of the AlpFUTUR core team proved beneficial. First, it was interdisciplinary, ensuring that each sub-project in the various disciplines had competent points of contact. Second, it included both men and women, combining different sorts of creativity and contacts. And third, it involved people who put the programme, projects and researchers first and valued the researchers' work. All this increases confidence, reduces hierarchies and destructive competition, and reinforces a sense of the common interest and the bigger picture. Yet, a core team with several members needs streamlined decision-making channels in order to avoid inefficiencies. It also emerged that decisions are ideally taken by consensus: on the one hand, this ensures that decisions are based on adequate exchange of information; on the other hand, this leadership culture pervades the entire programme.

Successful involvement of key players, including collaboration and empowerment, requires their integration at an early stage, huge efforts to build contacts and confidence, and sensitivity to a balance between involving and over-burdening.

A thorough workshop preparation, strictly run meetings and high expectations in terms of inputs and discussion of content were found to be conducive to the research process and the atmosphere within the programme.

The media activities crucial for the programme's implementation were undertaken by AlpFUTUR with the aid of professional media agencies (WSL and Agroscope). This substantially increased the effectiveness of communication towards the outside.

Furthermore, the interests and experience of the individual researchers involved played a key role: since inter- and transdisciplinarity implies a great deal of time and effort in listening to others and familiarising oneself with different fields, it is essential to work with researchers who are experienced in, or have an affinity for this.

Finally, AlpFUTUR found it helpful to consult relevant literature on how to structure and manage a transdisciplinary research programme (e.g., Defila et al. 2006), as well as to consider the experience acquired in ongoing and completed transdisciplinary projects (mainly via conversations). 


\section{Conclusions}

AlpFUTUR was created as a controlled bottom-up process regarding research questions and practice-related issues. The programme and the individual research projects were developed on the basis of research questions identified by experts and practitioners, researchers' questions and knowledge, and the core team's understanding of Alpine farming. The search for funding was carried out by researchers and core team; the latter devised, organised and coordinated the networking and communication processes, designed the programme and synthesis work, and contributed to quality assurance.

Key players from practice and government participated in AlpFUTUR from the outset. Some who were initially sceptical about the project (see above p. 192) became committed over time. Mutual understanding of each party's concerns and expectations required patience and repeated discussion. The varied origins of the audience at the closing event - from practising alpine farmers, to a historian, to senior government representatives - illustrated the interest in Swiss Alpine farming and the expectation that AlpFUTUR would yield useful results. The feedback received, continuing interest in the results, and the huge media response suggest that AlpFUTUR succeeded in meeting these expectations. The final synthesis published in three languages (Lauber et al. 2013) ${ }^{5}$ has attracted over 1,400 requests for printed copies, as well as multiple online requests, so far.

We thank the 80 researchers and 54 funding institutions who made AlpFUTUR possible. Thanks go also to Priska Baur for the idea of launching a transdisciplinary programme on the Swiss summer grazing areas; she has worked on the implementation of this idea for more than a year, made an important first status report (Baur et al. 2007), and together with Felix Herzog, she prepared the ground for AlpFUTUR.

\section{References}

Baur, P., P. Müller Wahl, F. Herzog. 2007. Alpweiden im Wandel. Agrarforschung 14/6: 254-259.

Berger, W., V. Winiwarter, G. Dressel, K. Heimerl. 2014. Methoden und Praktiken interdisziplinärer und transdisziplinärer Wissenschaft. In: Interdisziplinär und transdisziplinär forschen: Praktiken und Methoden. Edited by G. Dressel, W. Berger, K. Heimerl, V. Winiwarter. Bielefeld: transcript. 17-28.

Brandt, P. et al. 2013. A review of transdisciplinary research in sustainability science. Ecological Economics 92: 1-15.

Defila, R., A. Di Giulio, M. Scheuermann. 2006. Forschungsverbundmanagement. Handbuch für die Gestaltung inter- und transdisziplinärer Projekte. Zurich: vdf Hochschulverlag.

Dressel, G., W. Berger, K. Heimerl, V. Winiwarter (Eds.). 2014. Interdisziplinär und transdisziplinär forschen: Praktiken und Methoden. Bielefeld: transcript.

Hirsch Hadorn, G. et al.(Eds.). 2008. Handbook of transdisciplinary research. Heidelberg: Springer.

Huber, R., A. Rigling. 2014. Commitment to continuous research is a key factor in transdisciplinarity: Experiences from the Mountland project. GAIA 23/3: 256-262.

5 At www.alpfutur.ch/alpfutur the book is available online in three Swiss official languages (German, French and Italian).
Lang, D. et al. 2012. Transdisciplinary research in sustainability science: Practice, principles, and challenges. Sustainability Science 7/1: 25-43.

Lauber, S., I. Seidl, R. Böni, F. Herzog. 2008. Sömmerungsgebiet vor vielfältigen Herausforderungen. Agrarforschung 15/11-12: 548-553.

Lauber, S. et al. (Eds.). 2013. Zukunft der Schweizer Alpwirtschaft. Fakten, Analysen und Denkanstösse aus dem Forschungsprogramm AlpFUTUR. Birmensdorf/ Zurich-Reckenholz: Eidg. Forschungsanstalt für Wald, Schnee und Landschaft (WSL)/Forschungsanstalt Agroscope Reckenholz-Tänikon ART.

Pohl, C., G. Hirsch Hadorn. 2007. Principles for designing transdisciplinary research proposed by the Swiss Academies of Arts and Sciences. Munich: oekom.

Ukowitz, M. 2014. Towards a theory of transdisciplinary research. GAIA 23/1: $19-22$.

Werthemann, A., A. Imboden. 1982. Die Alp- und Weidewirtschaft in der Schweiz. Schlussband Schweizerischer Alpkataster. Zusammenfassung der kantonalen Publikationen 1962-1976. Berne: Bundesamt für Landwirtschaft.

Winiwarter, V. 2014. Designing trans-disciplinary projects for sustainable development. In: The role of natural heritage for the sustainable development of the Danube Region. Edited by S. Brumat, C. Macchia. DIAnet International School Proceedings 2014. Trieste: Edizioni Università di Trieste (EUT). 45-59.

Submitted December 20, 2014; revised version accepted July 2, 2015.

\section{Irmi Seidl}

Born 1962 in Holzkirchen, Germany. 1993 PhD in management sciences, 2002 habilitation in environmental sciences. Head of Research Unit Economics and Social Sciences at Swiss Federal Research Institute for Forest,

Snow and Landscape Research WSL, Birmensdorf,

Switzerland. 2007 to 2014 core team and research in AlpFUTUR. Research interests: spatial development, biodiversity and nature conservation, post-growth society.

Rosa Böni

Born 1959 in Richterswil, Switzerland. Diploma in natural resource sciences. 2007 to 2012 core team and research in AlpFUTUR at Swiss Federal Research Institute for Forest, Snow and Landscape Research WSL, Birmensdorf, Switzerland. Since 2012 project coordinator at the UNESCO World Heritage Swiss Tectonic Arena Sardona, Sargans, Switzerland. Research interests: research and monitoring in Natural World Heritage Sites.

Stefan Lauber

Born 1975 in Lucerne, Switzerland. PhD in agricultural economics. 2007 to 2014 core team (coordinator) and research in AlpFUTUR at Swiss Federal Research Institute

for Forest, Snow and Landscape Research WSL, Birmensdorf, Switzerland. Since 2014 head of the environment and energy department of the municipal administration of Kriens, Switzerland. Areas of expertise: agricultural economics, agricultural structural change, environmental law enforcement.

Felix Herzog

Born 1960 in Pratteln, Switzerland. 1992 PhD in agronomy. Research in landscape ecology at Helmholtz Centre for Environmental Research - UFZ, Leipzig, Germany. Since 2000 research group leader at Agroscope, Zurich, Switzerland. 2007 to 2014 core team and research in

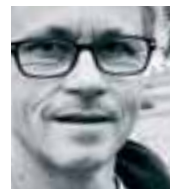
AlpFUTUR. Research interests: interface between productive agriculture, landscape ecology and ecosystem services. 